\title{
Design and Peformance Test of Coconut Skin Testa Peeling Machine
}

\author{
Yukodharma Putra, Erry Rimawan, Ahmad Rusdi, Andrianto \\ Magister Management ${ }^{1}$, Magister Industrial Engineering ${ }^{2,3,4}$ \\ Mercu Buana University, Jakarta State, Indonesia
}

\begin{abstract}
Coconut nicknamed "Tree of Life" because it is a multi-purpose agricultural commodities in which all parts of the coconut plants are beneficial to humans. One of the results of the coconut is coconut oil. To get the oil required several processes such as coconut testa peeling the skin. Coconut testa skin peeling process is still done manually using a special knife that takes time and considerable manpower. In addition, there is a risk of a knife scraped manually peeling process. It required skinner testa machine to increase production capacity and avoid the risks that occur when using the manual method.
\end{abstract}

Skinner testa machine design results can peel testa with peeling efficiency of $90 \%$ with the time it takes for 15 minutes to peel as many as 20 coconuts. Costs for skin peeling coconut testa cheaper than the manual that is $R p 91.9$ for a one coconut.

Keywords:- Coconut, Skin Testa, Peeling Process.

\section{INTRODUCTION}

Indonesia is an agricultural country that has a fairly large area. A variety of plants are found in Indonesia, which is well known to the world market. Large enough land can have a positive impact on Indonesian agriculture. Therefore, Indonesian agricultural products are quite well known both in the local and foreign regions. One of Indonesia's abundant commodities is coconut. The most commonly grown coconuts in Indonesia are deep coconut and hybrid coconut.

Coconut is one of the plantation commodities which has a large production in Indonesia. Based on data obtained from the Ministry of Agriculture, in 2015 to 2017(Pertanian 2019), the average annual production is 2,893,045 tons of coconut which it produces annually in all provinces in Indonesia. Of the total coconut production in Indonesia, $34.7 \%$ is processed into coconut milk, $8 \%$ for oil and $57.3 \%$ for copra (Pertanian 2005). Based on the data, coconut production will increase along with demand for coconuts. With the increase in production, several machines are needed to help the process of handling pre-harvest and post-harvest coconut. Some parts of the coconut must be separated in order to get the coconut ready for further processing. Some parts that must be removed are outer skin, coir, shell and flesh skin (testa skin).
One of the results of the coconut processing is coconut milk. Coconut milk is the result of processing grated coconut meat which is then squeezed and added water. Processed coconut meat must have skin peeled. The process of peeling coconut fruit is generally peeling coconut fibers, coconut shells and peeled coconut skin to get the whole coconut meat. Testa is the part that protects the flesh of the fruit with a shell. In general, testa skin will be discarded and used as animal feed. Testa skin will make the results of coconut milk is not good. (Appaiah et al. 2014).

Testa skin is the skin found on the outside of the coconut flesh which is not useful if the fruit flesh wants to be processed. The process of separation from the skin of the meat is still done manually. The process of separation from the skin of the meat using a manual knife and by peeling. Testa skin stripping by manual will require a long time and a lot of labor. So we need a machine to peel the skin of the coconut testa to produce coconut that is good in terms of quality for further processing.

\section{LITERATURE REVIEW}

\section{$>$ Coconut}

In general, coconuts have a composition of $35 \%$ coir, $12 \%$ shell, $28 \%$ seed meat, and $25 \%$ coconut water. However, this composition varies greatly depending on the type of coconut. Coconut fruit can generally be harvested after 11-12 months after female flowers are pollinated(Samosir 1992). A normal coconut fruit consists of several parts, namely outer skin (epicarp), coir (mesocarp), shell (endocarp), fruit skin (testa), fruit flesh (endosperm), coconut water and institutions (Palungkun 1998).

Coconut skin is found after the coconut shell is separated. Coconut flesh skin (testa skin) is the skin attached to the coconut flesh (Palungkun 1998). Testa skin is generally brown. This skin is generally removed when the fruit flesh will be processed because if the skin is included in the processing of oil will cause the oil to brown.

\section{$>$ Peeling Principle \\ Peeling process is an activity that aims to separate the skin from the flesh. The peeling method is divided into manual peeling by hand, as well as mechanical peeling. The peeling process must not change the shape of the chemical condition of the product to be peeled. Currently the process of peeling the skin of the coconut flesh (testa skin) is still using hands and with a special knife. The peeling process used to peel the skin of the coconut testa using a rotating}


drum. The principle of peeling used is the friction between the coconut with the drum and the friction between the coconut. The principle used resembles the principle of peeling the cassava peel. However, the cassava peeler was given an abrasive to peel the cassava peels of (Engineering 2006) .The drum rotates at a certain speed and the inside of the rotating drum is made rough so it is able to peel the skin of the coconut testa.

\section{METODOLOGY}

The stages of the research carried out are as follows:

\section{$>$ Identification of problems}

At this stage the characteristics of the coconut fruit (dimensions, weight and thickness of the skin) will be identified, how to manually strip the skin of the testa, as well as several alternative mechanisms that will be used for the machine to be made.

\section{$>$ Formulation of Design Concepts}

Analysis of the existing problems and some alternative concepts that can be used while considering related aspects. In this stage several functional and structural designs will be produced. The functional design that will be designed is the function of peeling coconut skin This function is carried out by two cylinders which rub against the skin of the coconut testa.

In designing and building a coconut peeling machine some of the expected criteria are as follows:

- Being able to peel the skin of the coconut testa cleanly

- Easy to operate

Conceptual design of testa skin peeling machine using a rotating drum mechanism. By using a rotating drum it is expected that the skin of the testa can be peeled off. The principle uses friction between the drum and coconut skin. In addition, friction between coconuts is also expected to be able to peel the skin of the coconut. The rotating drum is made of perforated stainless steel plates. The hole of the stainless steel plate is one centimeter with the distance between the holes one centimeter. On the inside of the rotating drum mounted cylinder buffer is also installed. It aims to avoid coconut thrown back so that the coconut will not break. The distance between the peeling cylinder and the supporting cylinder is set as wide as $15 \mathrm{~cm}$. this refers to the average size of coconut diameter of $11 \mathrm{~cm}$.

\section{Technical Analysis}

Technical analysis is done to get the dimensions of each component, the power needed, and so on. Analysis of the design consists of functional analysis and structural analysis. Functional analysis explains the functions of each component on the machine. Structural analysis explains the material selection, power and power analysis and material strength analysis. The entire technical calculation uses the approach of determining the elements (Sularso 2004)
The motor power driving the coconut testa peeling machine uses a minimum motor with a power of $0.9 \mathrm{hp}$. So that the motor used as a driving machine for peeling coconut testa uses an electric motor with a power of $1 \mathrm{hp}$.

The machine's frame is made of $\mathrm{L}$ profile steel which functions as a load enforcer and weight. The profile material used in making this machine frame is ST 37 carbon steel with a size of $40 \mathrm{x} 40 \mathrm{~mm}$ and a thickness of $1.5 \mathrm{~mm}$. The coconut peel paring machine has a dimension of $900 \mathrm{~mm}$ in length, $720 \mathrm{~mm}$ in width and $1000 \mathrm{~mm}$ in height.

The rotating drum of a coconut testa skin peeling machine is made of a perforated stainless steel plate with a hole size of $1 \mathrm{~cm}$. The size of the drum is determined based on the characteristics of the coconut to be peeled. The average diameter of a coconut is $11 \mathrm{~cm}$ so to get 10 coconuts the drum is made with a length of about $700 \mathrm{~mm}$ and a diameter of $600 \mathrm{~mm}$.

The shaft used as drum drum uses carbon steel construction S40C engine which has a tensile strength of 55 $\mathrm{kg} / \mathrm{mm} 2$. The diameter of the shaft used is $32 \mathrm{~mm}$ and the diameter of the bearing is $35 \mathrm{~mm}$ with a keyway $7 \times 4 \times 0.4$.

The supporting cylinder serves to hold the coconut from being thrown inside the drum. The supporting cylinder is made using the same perforated stainless steel plate as the drum. The size of the supporting cylinder is adjusted to the size of the coconut. So that there is no coconut that is depressed by the supporting cylinder. The size of the supporting cylinder has a diameter of $250 \mathrm{~mm}$.

The water reservoir in the coconut peel machine serves to soften the skin of the testa so that the skin of the testa can be peeled off. In addition, the reservoir water also functions to wash the coconut that has been peeled into the skin of the testa so that maximum results are obtained. Tubs of water are made with stainless steel plates, where at the bottom are given eject holes. The drain hole serves to dispose of water after the stripping process is complete. The stainless steel plate used is type 304 with a plate thickness of around $1.2 \mathrm{~mm}$. In the drain hole water is made from napple with a size of 1 inch with a lid from DOP.

The belt is used to transmit power from the gearbox pulley to the shaft pulley from the peeling drum using a belt and pulley transmission which will vary the rotational speed of the drum. Calculation of V-belt transmission can be seen in Appendices 6,7 and 8. Axis are $500 \mathrm{~mm}$. In addition, the power transmission system from the motor to the gearbox uses type A belts with a drive pulley diameter of 4 inches and a driven pulley diameter of 5 inches with a distance between the axle axis of $450 \mathrm{~mm}$.

The shaft used as a drum drive uses stainless steel. The shaft diameter used is $32 \mathrm{~mm}$ and using a bearing with number 6307. 


\section{Engineering drawings}

Engineering drawing is a conceptual drawing of the machine that will be made with a size that has been adjusted by technical analysis. Technical drawings are also a communication medium to the manufacturer if the device or machine is to be fabricated. The picture below is the result of predetermined designs.

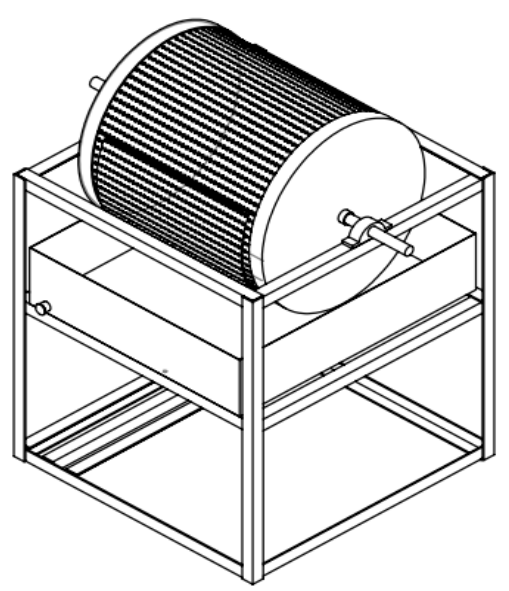

Fig 1:- Result Engineering Drawing

\section{$>$ Prototype Making}

The results of the design of the machine or generally in the form of technical drawings will be made in the prototype construction workshop. This prototype must be ensured to be tested according to the design that has been made. The picture below is the result of making a prototype of engineering drawing that has been made.

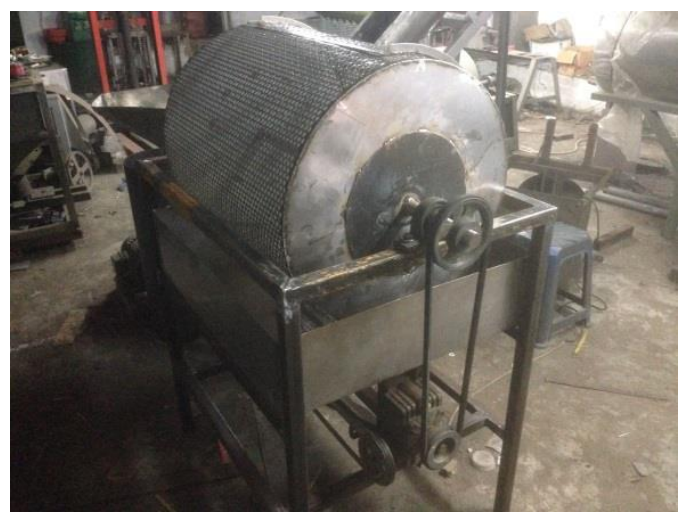

Fig 2:- Result Prototype Making

\section{Functional Test Machine}

At this stage the prototype that has been made will be tested whether it matches the function that has been designed.

\section{Engine Performance Test}

After all the functions of the machine are in accordance with the results of the design, then the next step is testing the performance of the engine. At this stage data will be taken when peeling the skin of the coconut testa, the rotary speed of the drum and the results of peeling. Data is collected using coconut whose skin has not been peeled. Then the peeling process is done by a peeling machine until the skin of the testa is peeled completely. After all data is obtained, then the cost of stripping services for coconut per coconut will be calculated.

\section{RESULT}

The results of the design concept of a coconut testa peeling machine design consists of several component functions aimed at peeling a coconut testa skin. The following are some of the functions of the components of the coconut peel machine.

\begin{tabular}{|c|c|c|}
\hline No & Component & Function \\
\hline 1 & Drum & Peeling coconut testa skin \\
\hline 2 & Support Cylinder & Hold the coconut so that it is not thrown in the drum \\
\hline 3 & Frame & Source of propulsion \\
\hline 4 & Electric motor & Power transmission from an electric motor to a rotating drum \\
\hline 5 & Pulley belt & Reducing the rotation of the electric motor \\
\hline 6 & Gearbox & Holds water, making the skin of the testa easier to peel \\
\hline 7 & Water tub & Table 1 \\
\hline
\end{tabular}

Table 1

The way the coconut testa skin peeling machine is designed is the operator filling the tub with water with a height of $19 \mathrm{~cm}$ from below the surface of the tub. The coconut to be peeled is put into the drum manually. After all the coconuts come in, then close the drum again. After that, the engine starts and the coconut will peel off because it rubs against the surface of the drum and rubs with the other coconut. Water in the tub serves to wash the coconut and soften the texture of the skin of the coconut testa. After the skin is removed, the coconut is removed from the drum manually to do the next process.

The next process is testing the performance of the machine, the following are the results of testing of the performance of the coconut peeling machine peel: 
ISSN No:-2456-2165

\begin{tabular}{|c|c|c|c|c|}
\hline Speed (RPM) & Number of coconuts (pcs) & Peeled coconut (pcs) & Unpeeled coconut (pcs) & Broken coconut (pcs) \\
\hline \multirow{3}{*}{50} & 10 & 5 & 3 & 2 \\
\hline & 15 & 10 & 5 & 0 \\
\hline & 20 & 17 & 3 & 0 \\
\hline \multirow{3}{*}{60} & 10 & 3 & 5 & 2 \\
\hline & 15 & 10 & 5 & 0 \\
\hline & 20 & 18 & 2 & 0 \\
\hline \multirow{3}{*}{70} & 10 & 5 & 5 & 0 \\
\hline & 15 & 10 & 3 & 2 \\
\hline & 20 & 5 & 0 & 15 \\
\hline
\end{tabular}

Table 2

Based on data that has been obtained from the results of the testing of the skin testa coconut. At a speed of 70 rpm, it is found that the number of coconuts added is greater so there will be coconuts which will break. This is due to the very fast rotating speed of the drum which makes the coconut spin rapidly so as to produce a large centrifugal force which causes the coconut to break. In addition, the large number of coconuts when rotated at a high enough speed will make the coconut thrown because of little space and the speed is quite high and a lot of water is wasted due to the drum's fast turning speed. At speeds of $50 \mathrm{rpm}$ and $60 \mathrm{rpm}$ is a good speed for peeling due to the result of the coconut breaking slightly.

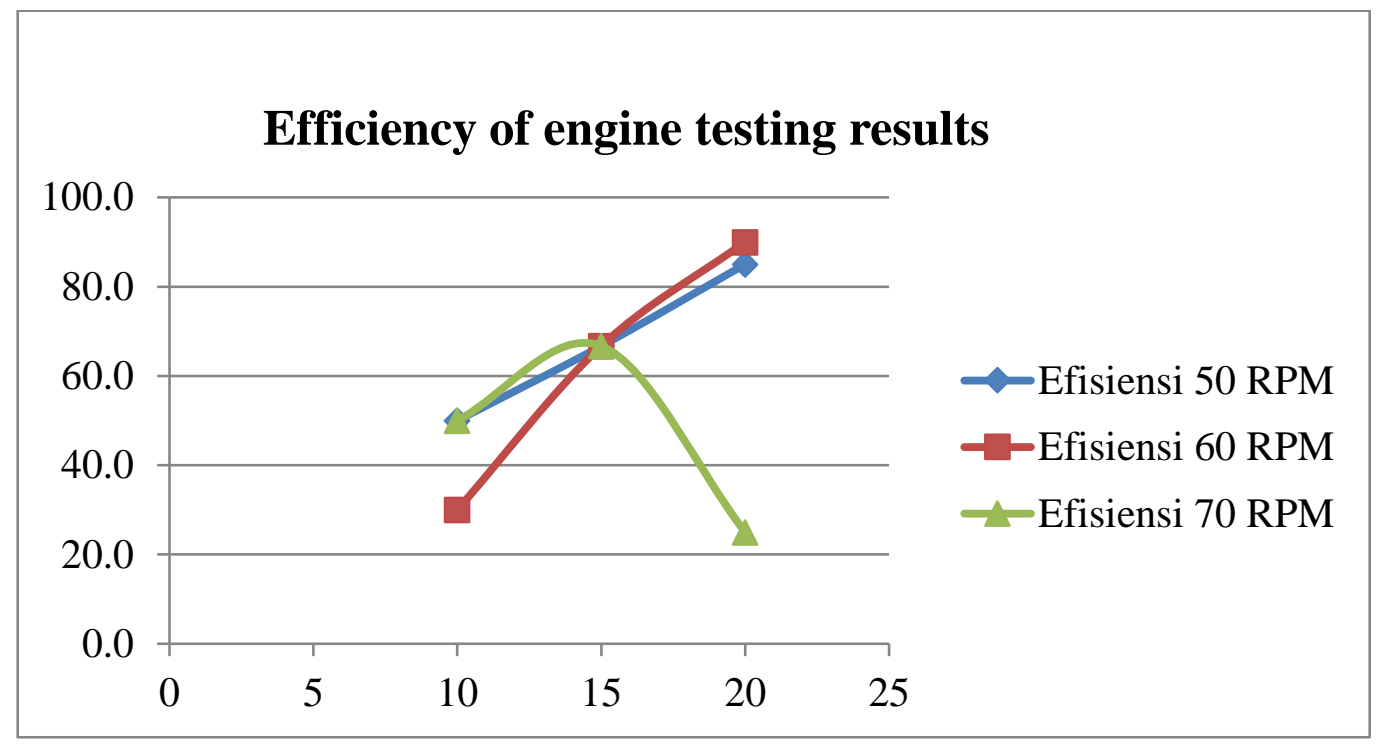

Fig 3

Peeling efficiency is calculated from the number of perfectly shelled coconuts divided by the total amount of coconuts put into the drum. The efficiency obtained can be seen in the Figure above. The graph shows that the greatest efficiency is produced by a drum speed of $60 \mathrm{rpm}$ with a total of 20 coconuts. Efficiency obtained around $90 \%$, which means that with a drum rotation speed of $60 \mathrm{rpm} 90$ percent of them peeled completely. The lowest efficiency is obtained by a drum speed of $70 \mathrm{rpm}$ with a total of 20 pieces with an efficiency value of around $25 \%$. This is due to the fairly fast drum speed and the space between the coconut trees is very narrow, so many coconuts are broken. Based on a fairly large stripping efficiency at a speed of 60 $\mathrm{rpm}$, the optimal speed for peeling the skin of the coconut is $60 \mathrm{rpm}$ with a total of 20 coconuts.

Based on the explanation above, it can be concluded that the machine was designed to be able to peel the skin of the coconut testa so as to obtain the whole coconut meat for further processing. In addition, the use of a machine that has been designed is capable of carrying out a stripping process with an efficiency of $90 \%$ with the time needed for 15 minutes. Previously the capacity needed in the process of stripping coconut testa 1000 grains required 8 hours (Rukmana 2003). Based on that, the use of a paring machine designed to be more effective and efficient because it can do the process of stripping 20 coconuts in 15 minutes.

After that, the cost needed to do the process of stripping the coconut skin manually is Rp 100 per pcs. Machines that have been designed produce a lower cost of basic items, namely Rp.91.9 per pcs. Basic costs are calculated based on fixed costs and variable costs. Based on these considerations, the design machine has been able to produce lower costs compared to using a manual knife. 


\section{CONCLUSION}

Based on the results obtained from this study, it can be concluded that:

$>$ Coconut testa skin peeling machine can peel coconut. But not all coconuts can be peeled off. The results are affected by coconut damage and the shape of the coconut itself. The results of stripping using a paring machine peel reached $90 \%$.

The time needed in the process of peeling the skin of the coconut testa using the machine design is longer than the manual. The time needed to peel the skin of the coconut testa using a machine is about 15 minutes for the number of coconuts 20 pieces or to peel one fruit takes about 1.33 minutes, while using a manual to peel the skin of the testa takes half a minute to peel the skin of the testa.

The basic cost for the process of stripping the testa skin using a machine designed is Rp. 91.9 per pes.

\section{REFERENCES}

[1]. Appaiah P, Sunil L, Prasanth Kumar PK, Gopala Krishna AG. 2014. Composition of coconut testa, coconut kernel and its oil. JAOCS, Journal of the American Oil Chemists' Society. 91(6):917924.doi:10.1007/s11746-014-2447-9.

[2]. Engineering A. 2006. Journal of Agricultural Engineering and Technology (JAET). Volume 14, 2006.

[3]. Palungkun R. 1998. Aneka Produk Olahan Kelapa. Jakarta: Penebar Swadaya.

[4]. Pertanian K. 2005. Pengolahan Kelapa. Jakarta.

[5]. Pertanian K. 2019. Data Lima Tahun Terkahir Sub Sektor Pertanian. Jakarta.

[6]. Rukmana R. 2003. Aneka Olahan Kelapa. [diunduh 2015 Nov 27]

[7]. Samosir Y. 1992. Asal Usul dan Botani Kelapa.

[8]. Sularso KS. 2004. Dasar-Dasar Perencanaan dan Pemilihan Elemen Mesin. Jakarta: PT. Pradya Paramita. 